\title{
An Analysis of the Influence of Fundamental Values' Estimation Accuracy on Financial Markets
}

\author{
Hiroshi Takahashi \\ Graduate School of Business Administration, Keio University, 4-1-1 Hiyoshi, Kohoku-ku, \\ Yokohama-city 223-8572, Japan \\ Correspondence should be addressed to Hiroshi Takahashi, htaka@kbs.keio.ac.jp
}

Received 14 September 2009; Revised 17 December 2009; Accepted 17 February 2010

Academic Editor: Edward Furman

Copyright (C 2010 Hiroshi Takahashi. This is an open access article distributed under the Creative Commons Attribution License, which permits unrestricted use, distribution, and reproduction in any medium, provided the original work is properly cited.

\begin{abstract}
This research analyzed the influence of the differences in the forecast accuracy of fundamental values on the financial market. As a result of intensive experiments in the market, we made the following interesting findings: (1) improvements in forecast accuracy of fundamentalists can contribute to an increase in the number of fundamentalists; (2) certain situations might occur, according to the level of forecast accuracy of fundamentalists, in which fundamentalists and passive management coexist, or in which fundamentalists die out of the market, and furthermore; (3) where a variety of investors exist in the market, improvements in the forecast accuracy could increase the number of fundamentalists more than the number of investors that employ passive investment strategy. These results contribute to clarifying the mechanism of price fluctuations in financial markets and also indicate one of the factors for the low ratio of passive investors in asset management business.
\end{abstract}

\section{Introduction}

A growing body of studies regarding asset pricing have been conducted, and many prominent theories have been proposed [1-4]. Along with the advancement of these theories, many arguments regarding securities investment in practical business affairs in finance have been actively discussed. The theory of asset pricing and investment strategy for shares are also currently being discussed with enthusiasm. The accurate valuation of fundamental values of investment grade assets is one of significant interest for those investors that actually make transactions in real financial markets. For example, many of institutional investors have a number of security analysts in their own companies in order to try to evaluate the fundamental values of each security.

Market efficiency is a central hypothesis in traditional asset pricing theories and there has been a large amount of discussion regarding it [5]. For example, in the Capital 
Asset Pricing Model (CAPM), which is one of the most popular asset pricing theories, equilibrium asset prices are derived on the assumption of efficient markets and rational investors. CAPM indicates that the optimal investment strategy is to hold market portfolio ${ }^{1}$ [2]. Since it is very difficult for investors to get an excess return in an efficient market, it is assumed to be difficult to beat market portfolio even though fundamental values are estimated correctly based on public information [2,6]. On the other hand, passive investment strategy, which tries to maintain an average return using benchmarks based on market indices, is consistent with traditional asset pricing theories and is considered to be an effective method in efficient markets. On the basis of such arguments, there has been growing interest in passive investment strategy in the practical business affairs of asset management. Many investors employ the passive investment strategy for their investment. $^{2}$

Recently, however, traditional financial theories have been criticized in terms of their explanation power and the validity of their assumptions. Behavioral finance has recently been in the limelight and many reports indicate that deviation from rational decision-making can explain anomalies which cannot be explained with traditional financial theories [7-10]. Generally, investor behavior which is assumed in behavioral finance has complicated rules for decision making compared to decision making based on expected utility maximization. For this reason, in many cases, it is difficult to derive the influence of investor behavior on prices analytically [11]. In order to take such investors behavior into account in analyzing financial markets, we need to introduce a different analytical method.

In the area of computer science, Agent-Based Modeling has been proposed as an effective approach to analyze the relation between microrules and macrobehavior [12]. This is a bottom-up approach that tries to describe macrobehavior of the entire system using local rules. This approach is appropriate for analyzing a multiagent system in which a great number of agents that act autonomously gather together. ${ }^{3}$ The agent-based approach is applied in a wide variety of study fields such as engineering and biology, and many reports have been made about analyses adopting this approach in the field of social science [1317].

In the background of the above-mentioned arguments, the purpose of this research is to clarify the influence of the difference in the forecast accuracy of fundamental values on financial markets by using the agent-based model for analysis. This analysis includes the relationship between fundamentalists that invest based on fundamentals and passive investment strategy. Section 2 describes the model used in this analysis. Section 3 shows the results of the analysis. Section 4 summarizes this paper.

\section{Model}

A computer simulation of the financial market involving 1000 investors was used as the model for this research. Shares and risk-free assets were the two types of assets used along with the possible transaction methods. Several types of investors exist in the market, each undertaking transactions based on their own stock evaluations. This market was composed of three major stages, (1) generation of corporate earnings, (2) formation of investor forecasts, and (3) setting transaction prices. The market advances through repetition of these stages. The following sections describe negotiable transaction assets, modeling of investor behavior, setting transaction prices, and natural selection rules in the market. 
Table 1: List of investor types.

\begin{tabular}{lc}
\hline No. & Investor types \\
\hline 1 & Fundamentalist \\
2 & Forecasting by past average (most recent 10 days) \\
3 & Forecasting by trend (most recent 10 day) \\
4 & Passive investor \\
\hline
\end{tabular}

\subsection{Negotiable Assets in the Market}

This market has risk-free and risk assets. There are risky assets in which all profits gained during each term are distributed to the shareholders. Corporate earnings $\left(y_{t}\right)$ are expressed as $y_{t}=y_{t-1} \cdot\left(1+\varepsilon_{t}\right)$. However, they are generated according to the process of $\varepsilon_{t} \sim N\left(0, \sigma_{y}^{2}\right)$ with share trading being undertaken after the public announcement of profits for the term [18]. Each investor is given common asset holdings at the start of the term with no limit placed on debit and credit transactions (1000 in risk-free assets and 1000 in stocks). Investors adopt the buy-and-hold method for the relevant portfolio as a benchmark ${ }^{4}$ to conduct decision-making by using a one-term model.

\subsection{Modeling Investor Behavior}

Each type of investor handled in this analysis is organized in Table $1 .^{5}$ The investors in this market evaluate transaction prices based on their own forecasts for market tendency, taking into consideration both risk and return rates when making decisions. Each investor determines the investment ratio $\left(w_{t}^{i}\right)$ based on the maximum objective function $\left(f\left(w^{i} t\right)\right)$ as shown below ${ }^{6}[19]$ :

$$
f\left(w_{t}^{i}\right)=r_{t+1}^{\mathrm{int}, i} \cdot w_{t}^{i}+r_{f} \cdot\left(1-w_{t}^{i}\right)-\lambda\left(\sigma_{t-1}^{s, i}\right)^{2} \cdot\left(w_{t}^{i}\right)^{2}
$$

Here, $r_{t+1}^{\text {int }, i}$ and $\sigma_{t-1}^{s, i}$ express the expected rate of return and risk for stocks as estimated by each investor $i . r_{f}$ indicates the risk-free rate. $w_{t}^{i}$ represents the stock investment ratio of the investor $i$ for term $t$.

The expected rate of return for shares is calculated as follows [19]:

$$
r_{t+1}^{\mathrm{int}, i}=\frac{1 \cdot c^{-1}\left(\sigma_{t-1}^{s, i}\right)^{-2} \cdot r_{t+1}^{f, i}+1 \cdot\left(\sigma_{t-1}^{s, i}\right)^{-2} \cdot r_{t}^{i m}}{1 \cdot c^{-1}\left(\sigma_{t-1}^{s, i}\right)^{-2}+1 \cdot\left(\sigma_{t-1}^{s, i}\right)^{-2}}
$$

Here, $r_{t+1}^{f, i} C r_{t}^{i m}$ expresses the expected rate of return, calculated from short-term expected rate of return, and risk and gross current price ratio of stocks, respectively. $c$ is a coefficient that adjusts the dispersion level of the expected rate of return calculated from risk and gross current price ratio of stocks [19]. 
The short-term expected rate of return $\left(r_{t}^{f, i}\right)$ is obtained where $\left(P_{t+1}^{f, i}, y_{t+1}^{f, i}\right)$ is the equity price and profit forecast for term $t+1$ is estimated by the investor, as shown below:

$$
r_{t+1}^{f, i}=\left(\frac{P_{t+1}^{f, i}+y_{t+1}^{f, i}}{P_{t}}-1\right) \cdot\left(1+\eta_{t}^{i}\right) .
$$

The short-term expected rate of return includes the error term $\left(\eta_{t}^{i} \sim N\left(0, \sigma_{n}^{2}\right)\right)$ reflecting that even investors using the same forecast model vary slightly in their detailed outlook. The stock price $\left(P_{t+1}^{f, i}\right)$, profit forecast $\left(y_{t+1}^{f, i}\right)$, and risk estimation methods are described in Section 2.2.2.

The expected rate of return obtained from stock risk and so forth is calculated from stock risk $\left(\sigma_{t-1}^{i}\right)$, benchmark equity stake $\left(W_{t-1}\right)$, investorsf degree of risk avoidance $(\lambda)$, and risk-free rate $\left(r_{f}\right)$, as shown below $[19,20]$ :

$$
r_{t}^{i m}=2 \cdot \lambda \cdot\left(\sigma_{t-1}^{i}\right)^{2} \cdot W_{t-1}+r_{f}
$$

\subsubsection{Stock Price Forecasting Method}

The fundamental value is estimated by using the dividend discount model, which is a wellknown model in the field of finance. Fundamentalists estimate the forecasted stock price and forecasted profit from profit for the term $\left(y_{t}\right)$ and the discount rate $(\delta)$ as $P_{t+1}^{f, i}=y_{t} / \delta$, $y_{t+1}^{f, i}=y_{t}$.

Forecasting based on trends involves forecasting the next term stock prices and profit through extrapolation of the most recent stock value fluctuation trends. The next term stock price and profit is estimated from the most recent trends of stock price fluctuation $\left(a_{t-1}\right)$ from time point $t-1$ as $P_{t+1}^{f, i}=P_{t-1} \cdot\left(1+a_{t-1}\right)^{2}, y_{t+1}^{f, i}=y_{t} \cdot\left(1+a_{t-1}\right)$.

Forecasting based on past averages involves estimating the next term stock prices and profit based on the most recent average stock value.

\subsubsection{Risk Estimation Method}

In this analysis, each investor estimates risk from past price fluctuations. Specifically, stock risk is estimated as $\sigma_{t-1}^{i}=\sigma_{t-1}^{h}$ (common to each investor). Here, $\sigma_{t-1}^{h}$ represents the stock volatility that is calculated from price fluctuation from the most recent 100 terms.

\subsection{Determination of Transaction Prices}

Transaction prices are determined as the price where stock supply and demand converge $\left(\sum_{i=1}^{M}\left(F_{t}^{i} w_{t}^{i}\right) / P_{t}=N\right)$. In this case, the total asset $\left(F_{t}^{i}\right)$ of investor $i$ is calculated from transaction price $\left(P_{t}\right)$ for term $t$, profit $\left(y_{t}\right)$ and total assets from the term $t-1$, stock investment ratio $\left(w_{t-1}^{i}\right)$, and risk-free rate $\left(r_{f}\right)$, as $F_{t}^{i}=F_{t-1}^{i} \cdot\left(w_{t-1}^{i} \cdot\left(P_{t}+y_{t}\right) / P_{t-1}+\left(1-w_{t-1}^{i}\right) \cdot\left(1+r_{f}\right)\right)$. 


\subsection{Rules of Natural Selection in the Market}

The rules of natural selection can be identified in this market. The driving force behind these rules is cumulative excess profit [21]. The rules of natural selection go through the following two stages: (1) the identification of investors who alter their investment strategy, and (2) the actual alteration of investment strategy $[17,22]$.

Each investor determines the existence of investment strategy alteration based on the most recent performance of each 5 -term period after 25 terms have passed since the beginning of market transactions. The higher the profit rate obtained most recently is, the lesser the possibility of strategy alteration becomes. The lower the profit, the higher the possibility becomes. Specifically, when an investor could not obtain a positive excess profit for the benchmark portfolio profitability, they are likely to alter their investment strategy with the probability below: ${ }^{7}$

$$
p_{i}=\min \left(1, \max \left(-100 \cdot r^{\mathrm{cum}}, 0\right)\right) \text {. }
$$

Here, however, $r_{i}^{\text {cum }}$ is the cumulative excess profitability for the most recent benchmark of investor $i$. Measurement was conducted for 1 term, 5 terms, and 25 terms, and the cumulative excess profitability was a profitability of one-term conversion.

Regarding the determination of a new investment strategy, an investment strategy that has a high cumulative excess profit for the most recent five terms (forecasting type) is more likely to be selected. Where the strategy of the investor $i$ is $z_{i}$ and the cumulative excess profit for the most recent five terms is $r_{i}^{\text {cum }}$, the probability $p_{i}$ that $z_{i}$ is selected as a new investment strategy is given as $p_{i}=e^{\left(a \cdot r_{i}^{\text {cum }}\right)} / \sum_{j=1}^{M} e^{\left(a \cdot r_{j}^{\text {cum }}\right)} \cdot 8$ Those investors who altered their strategies make investments based on the new strategies after the next step.

\section{Analysis Results}

First of all, the case where investors make decisions based on past prices in the market is analyzed. Specifically, a market where there are investors that make forecasts based on past price trends and past price averages, as well as fundamentals, is analyzed. Afterwards, the case where there are investors that conduct passive investment strategy in the market is analyzed.

\subsection{Where There Exist Investors That Forecast Based on Past Price Fluctuations}

First of all, the influence of differences in the forecast accuracy of fundamentals on the market was analyzed. Afterwards, the influence of the difference in the forecast dispersion of investors other than fundamentalists was analyzed.

\subsubsection{Influence of the Difference in the Forecast Accuracy of Fundamentals}

This section analyzes the influence of the difference in the forecast accuracy of fundamentalists on the market where there exist heterogeneous investors in the market. From the start, there are a similar number of the three types of investors (Table 1: Type 1-3) in the market. In 


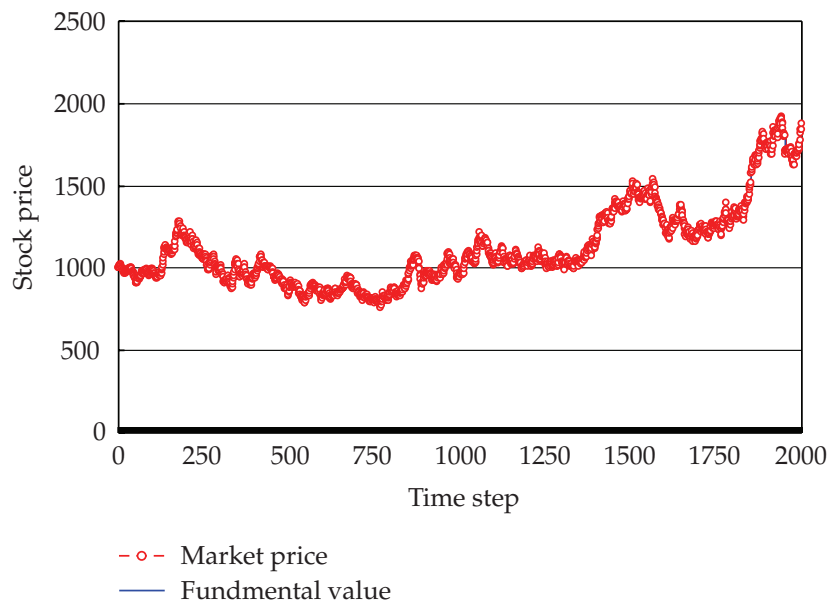

Figure 1: Price transitions $\left(\sigma_{n}=1 \%\right)$.

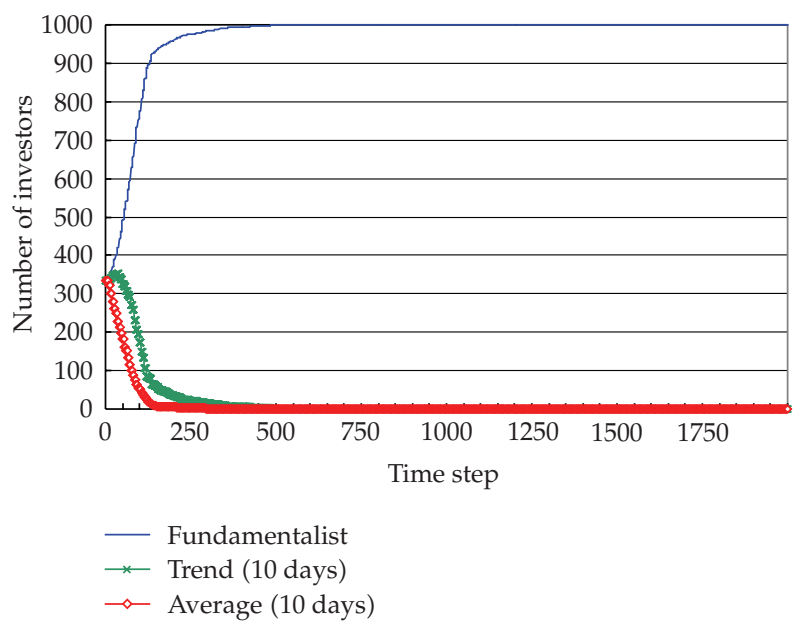

Figure 2: Transition of the number of investors $\left(\sigma_{n}=1 \%\right)$.

the beginning, the case where the forecast dispersion of investors $\left(\sigma_{n}\right)$ is $1 \%$ is described, and then the case where the forecast error of fundamentalists differs is described.

\section{Where the Forecast Dispersion of Investors Is 1\%}

Figures 1 and 2 show the transitions of transaction prices and the number of investors. The typical price transitions obtained in this analysis are shown with respect to the transition of transaction prices. With regard to the transition of the numbers of investors, the average value obtained by conducting the analysis 50 times was used (the same being true in the following analysis). Figure 1 shows that transaction prices are consistent with fundamental values throughout the entire transaction period. Figure 2 confirms that the number of fundamentalists increases as time goes on. 


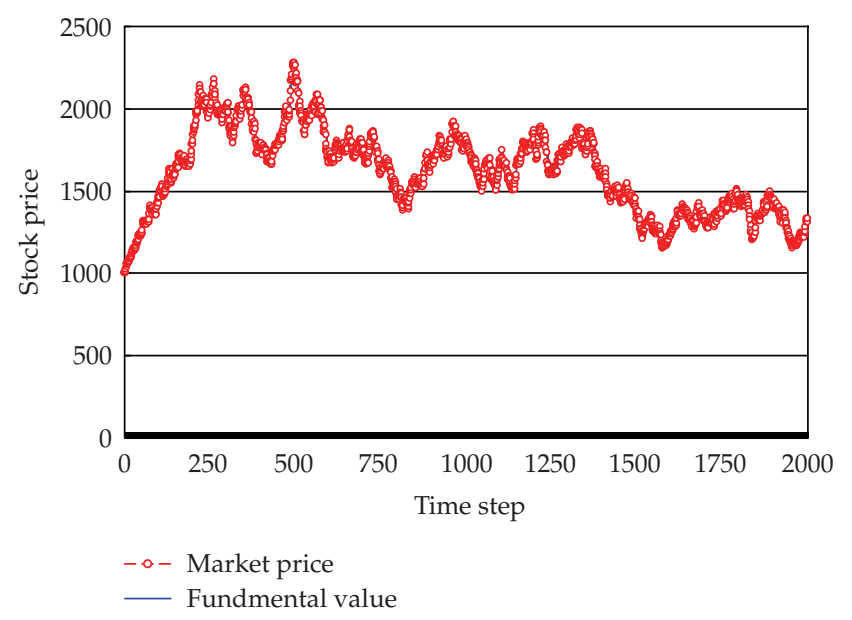

Figure 3: Price transitions $\left(\sigma_{n}=2 \%\right)$.

Where the Forecast Error of Fundamentalists Is 2\%

Figures 3 and 4 show the transaction prices and the transition of the number of investors where the forecast error of fundamentalists increases. In this analysis, the forecast error of fundamentalists $\left(\sigma_{n}\right)$ is $2 \%$, and the forecast dispersion of investors other than fundamentalists $\left(\sigma_{n}\right)$ is $1 \%$.

With respect to the transitions of transaction prices, as shown in Figure 3, it can be confirmed that transaction prices are consistent with fundamental values. Regarding the transition of the number of investors, similarly, the number of fundamentalists increases as time passes. When Figures 2 and 4 are compared regarding the rate of increase in the number of fundamentalists, the rate of increase is significant where fundamentalists have high accuracy in their forecasting. These results show that the better the forecast accuracy of fundamentalists becomes, the greater the rate of increase in the number of fundamentalists. The next section analyzes the case where the forecast error is $0 \% .{ }^{9}$

\section{Where the Forecast Error of Fundamentalists Is $0 \%$}

Figure 5 shows the transition of the number of investors where the forecast error of fundamentalists $\left(\sigma_{n}\right)$ is $0 \% .{ }^{10}$ The forecast dispersion of investors other than fundamentalists $\left(\sigma_{n}\right)$ is constant at $1 \%$. Where Figure 5 is compared with Figures 2 and 4 , the rate of increase of the number of fundamentalists is fastest in the case of Figure 5. When it comes to the rate of increase in the number of fundamentalists, the rate of increase goes up as the forecast accuracy improves. These results show that the better the forecast accuracy becomes, the more likely it is that fundamentalists can survive in the market. This result is consistent with traditional financial theory. The influence of the difference in the forecast accuracy of fundamentalists was analyzed in this analysis. Whether or not fundamentalists can survive in the market likely depends on the influence of the forecast dispersion of other investors. To confirm the influence of other investors, the next section analyzes the influence of forecast dispersion of investors other than fundamentalists. 


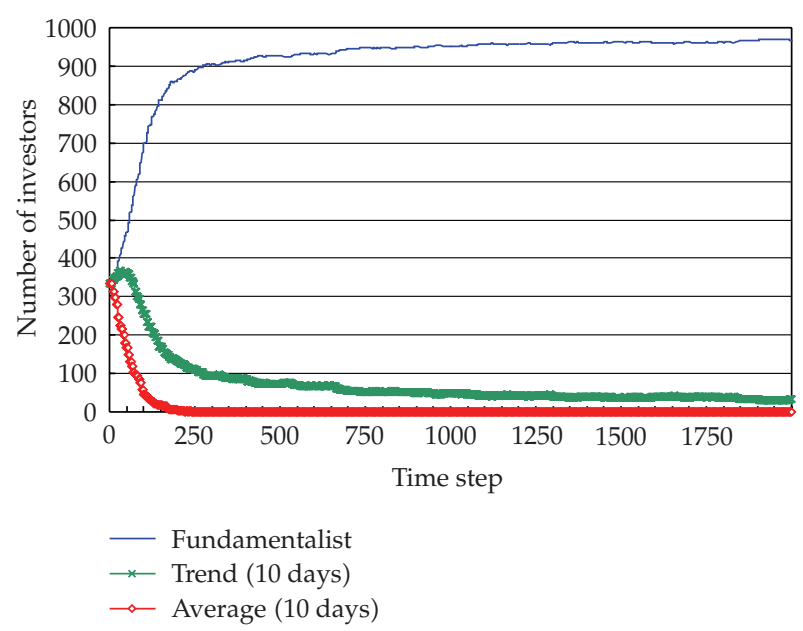

Figure 4: Transition of the number of investors $\left(\sigma_{n}=2 \%\right)$.

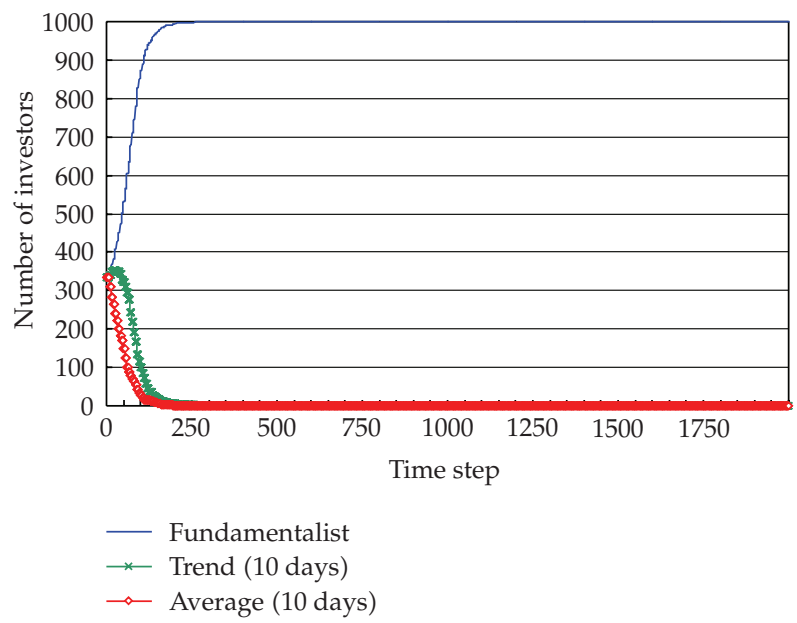

Figure 5: Transition of the number of investors $\left(\sigma_{n}=0 \%\right)$.

\subsubsection{Influence of Forecast Dispersion of Other Investors}

Here, the influence of forecast dispersion of other investors on the rate of increase in the number of fundamentalists is analyzed. The forecast accuracy of fundamentalists in this analysis $\left(\sigma_{n}\right)$ is consistent at $1 \%$.

Figures 6 and 7 show the transitions of the number of investors where the forecast dispersion of investors other than fundamentalists is $2 \%$ and $3 \%$. As the same with the previous section with respect to the transition of the number of investors, the number of fundamentalists increases as time passes. Furthermore, the rate of increase becomes faster as the dispersion of investors other than fundamentalists becomes significant. ${ }^{11}$ These results show that interaction with other investors should be taken into consideration in order to clarify the mechanism of financial markets. In this sense, these results are highly suggestive. ${ }^{12}$ 


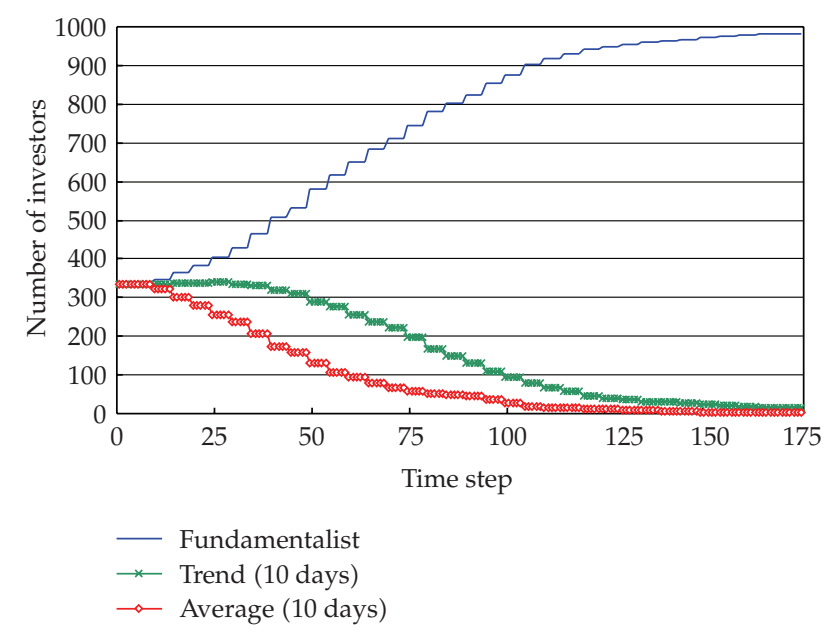

Figure 6: Transition of the number of investors $\left(\sigma_{n}=2 \%\right)$.

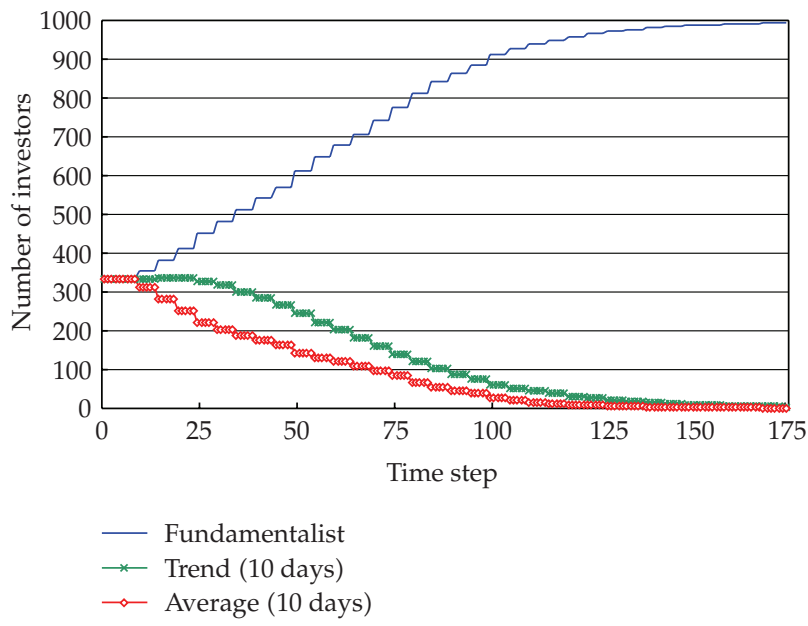

Figure 7: Transition of the number of investors $\left(\sigma_{n}=3 \%\right)$.

\subsection{Where There Exist Investors That Conduct Passive Investment Strategy}

This section analyzes the case where there exist investors that conduct passive investment strategy. First of all, the influence of the difference in the forecast accuracy of fundamentalists is analyzed, and then another analysis considers more practical conditions.

\subsubsection{Influence of the Difference in Forecast Accuracy of Fundamentalists}

This section analyzes the influence of differences in the forecast accuracy of fundamentalists on the market where there exist investors that conduct passive management. In the early stages, there are a similar number of the four types of investors (Table 1: Type 1-4) in the market. First of all, the case where the forecast dispersion of investors $\left(\sigma_{n}\right)$ is $1 \%$ is described. Afterwards, a case where the forecast error of fundamentalists is $0 \%$ is described. 


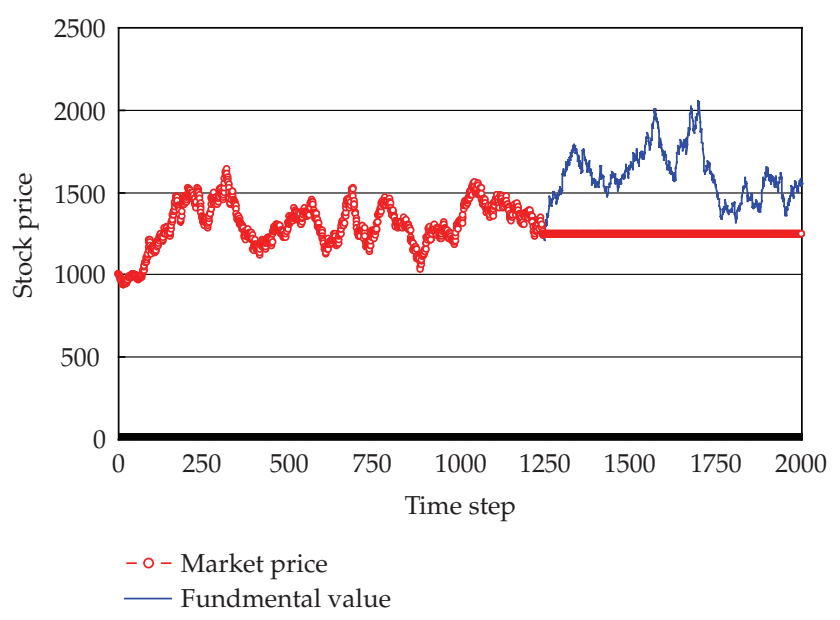

Figure 8: Price transitions $\left(\sigma_{n}=1 \%\right)$.

Where the Forecast Dispersion of Investors Is 1\%

Figures 8 and 9 show the transitions of transaction prices and the numbers of investors. Figure 9 shows that the number of investors that conduct passive investment strategy increases as time passes, and all the investors are conducting passive investment strategy after a certain period of time. ${ }^{13}$ These results support the effectiveness of conducting passive investment strategy from the viewpoint of investment performance, which is consistent with traditional asset pricing theories [2]. Transaction prices, however, do not show fundamental values from around the middle of the transaction period. The same trend can also be confirmed in the case where the forecast accuracy of fundamentalists is $2 \%$. Under the present conditions, the investment behavior of fundamentalists and passive management is the same on average. However, among fundamentalists, the number of investors that conduct passive investment strategy increases due to forecast error of fundamentalists. ${ }^{14}$ Where the forecast accuracy of fundamentalists is good, $\left(\sigma_{n}=0\right)$, coexistence of fundamentalists and passive management can be predicted. The next section analyzes the case where the forecast error of fundamentalists $\left(\sigma_{n}\right)$ is $0 \%$.

\section{Where the Forecast Error of Fundamentalists Is $0 \%$}

Figures 10 and 11 show the transitions of transaction prices and the number of investors where the forecast error of fundamentalists $\left(\sigma_{n}\right)$ is $0 \%$. In this analysis, the forecast dispersion of investors other than fundamentalists $\left(\sigma_{n}\right)$ is constant at $1 \%$. The price history shows that traded prices are consistent with fundamental values throughout the entire transaction period. Additionally, the transitions of the number of investors show that fundamentalists coexist with those investors that conduct passive investment strategy in the market. Just as with the present conditions, where there exist only two types of investors in the market, those investors that conduct passive investment strategy and fundamentalists, and where the forecast accuracy of fundamentalists is good $\left(\sigma_{n}=0\right)$, as a result, investment behavior of both investors becomes equal. Given this, both types of investors are likely to exist in the market. 


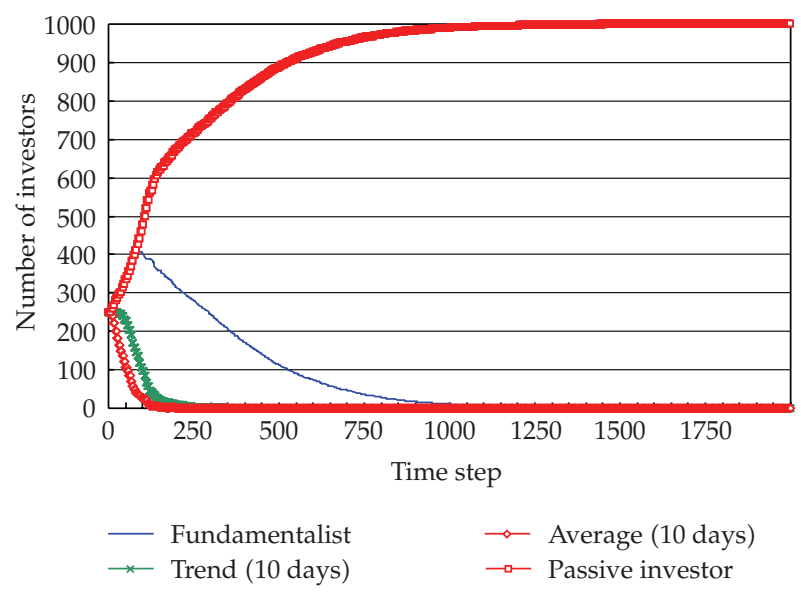

Figure 9: Transition of the number of investors $\left(\sigma_{n}=1 \%\right)$.

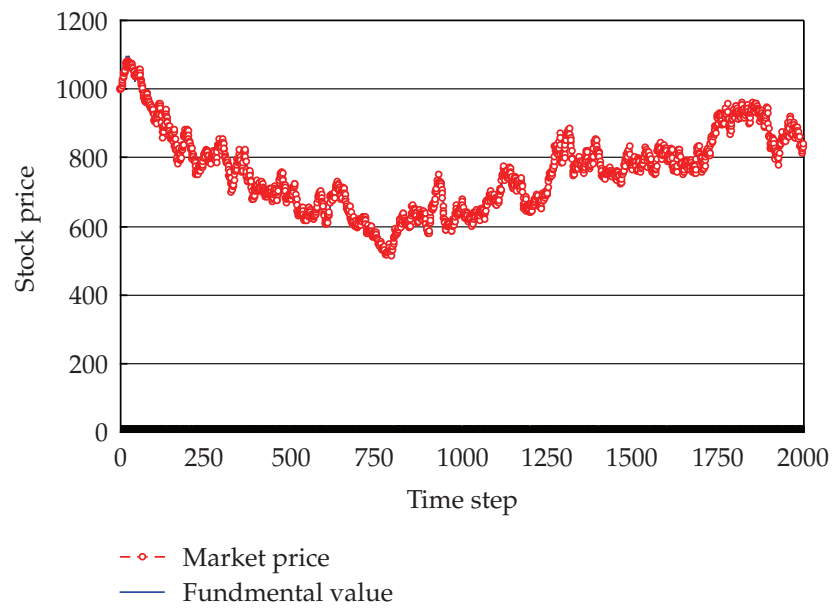

Figure 10: Price transitions $\left(\sigma_{n}=0 \%\right)$.

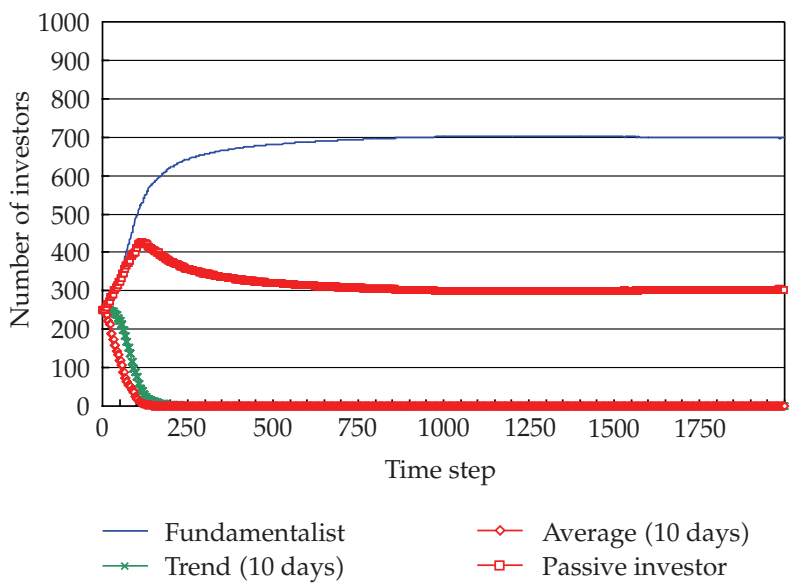

Figure 11: Transition of the number of investors $\left(\sigma_{n}=0 \%\right)$. 


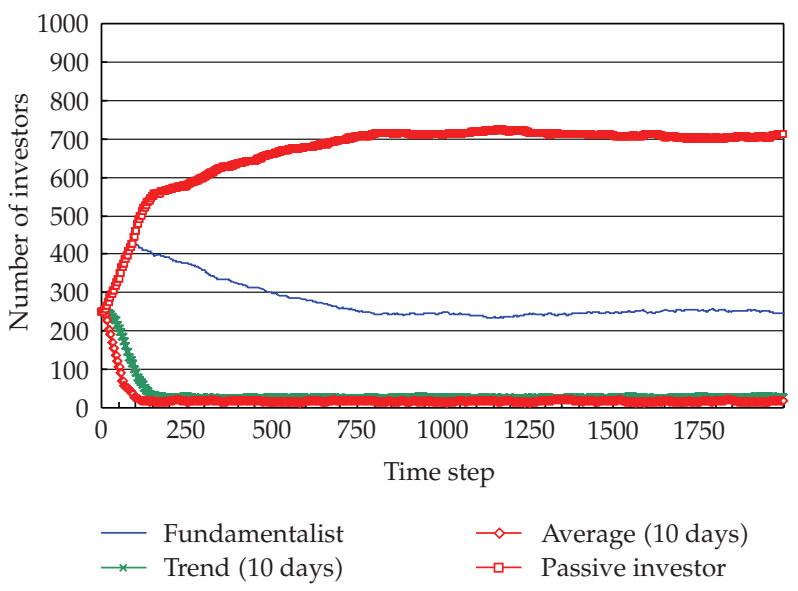

Figure 12: Transition of the number of investors (mutation: $1 \%, \sigma_{n}=1 \%$ ).

The analysis conducted in this section confirmed that different situations could be generated. For example, fundamentalists and investors who employ passive investment strategy coexisted in the market according to the forecast accuracy level of fundamentalists or fundamentalists could die out in the market. These results suggest that the difference in estimation accuracy of fundamentalists should have a significant impact on the market. Thus, the results obtained in this analysis are very interesting.

\subsubsection{Analysis That Considers the Actual Investment Environment}

This section conducts analysis under conditions close to that of actual market conditions. In real markets, investors do not always determine their investment strategy based only on past investment performance. This section focuses on how to change investment strategy in order to analyze the case where some investors randomly change investment strategy. ${ }^{15}$

First of all, the case where $1 \%$ of investors changes investment strategy in a random manner is analyzed. Afterwards, another case, where there is an increase in the rate of investors in changing investment strategy randomly, is analyzed. In the early stage, there are a similar number of the four types of investors (Table 1: Type 1-4) in the market. The forecast dispersion of investors other than fundamentalists $\left(\sigma_{n}\right)$ is constant at $(1 \%)$.

Where a 1\% of Investors Randomly Changes Investment Strategy

Figure 12 shows the transitions of the number of investors where the forecast accuracy of fundamentalists $\left(\sigma_{n}\right)$ is $1 \%$. This shows that fundamentalists and investors that conduct passive investment strategy coexist together in the market. ${ }^{16}$ Since investors who randomly change investment strategy exist, fundamentalists and passive investors coexist in the market when fundamentalists' forecasts are not entirely accurate. The existence of a wide variety of investors can make it possible for fundamentalists to obtain more excess earnings through market transactions. As a result, the number of fundamentalists probably increases. ${ }^{17}$ 


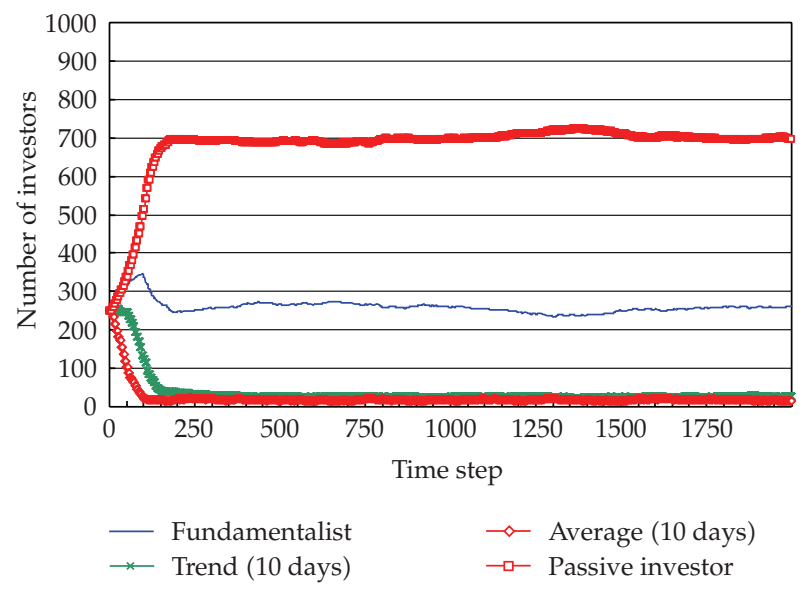

Figure 13: Transition of the number of investors (mutation: $1 \%, \sigma_{n}=2 \%$ ).

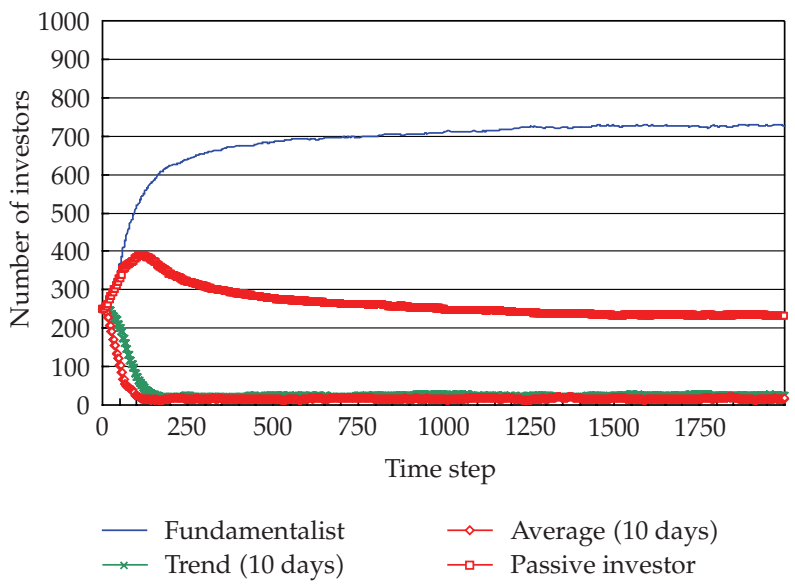

Figure 14: Transition of the number of investors (mutation: $1 \%, \sigma_{n}=0 \%$ ).

Figures 13 and 14 show the transitions of the number of investors where the forecast accuracy of fundamentalists is $2 \%$ and $0 \%$. These results can confirm that fundamentalists and investors that conduct passive investment strategy coexist. In addition, a comparison of Figures 13 and 14 shows that as the estimation accuracy of fundamentalists increases, there is a corresponding increase in the number of fundamentalists over time. These results are interesting. They show that the number of fundamentalists who can survive in the market is significantly influenced by the estimation accuracy level of fundamentalists.

Where the Rate of Investors That Randomly Change Investment Strategy Increases

Figure 15 shows the transitions of the number of investors where the rate of investors that randomly change investment strategy is $2 \% .{ }^{18}$ If there is an increase in the rate of 


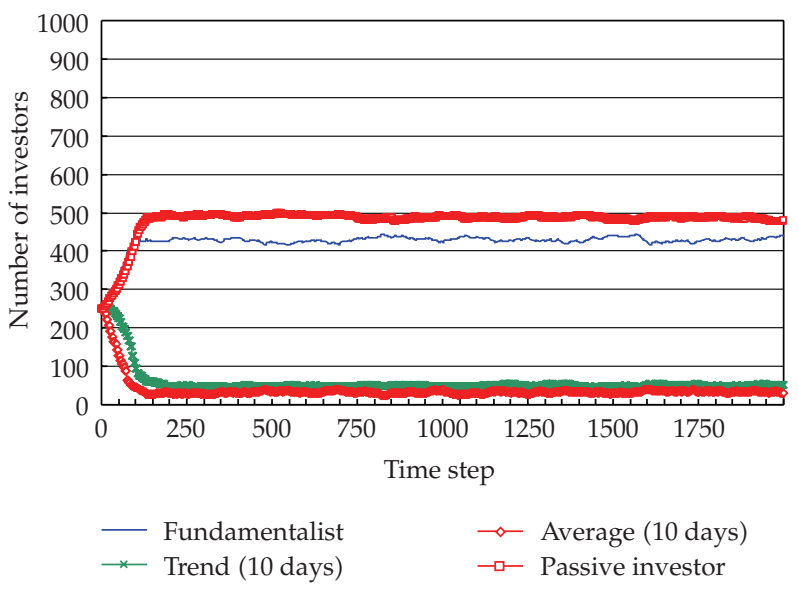

Figure 15: Transition of the number of investors (mutation: $2 \%, \sigma_{n}=1 \%$ ).

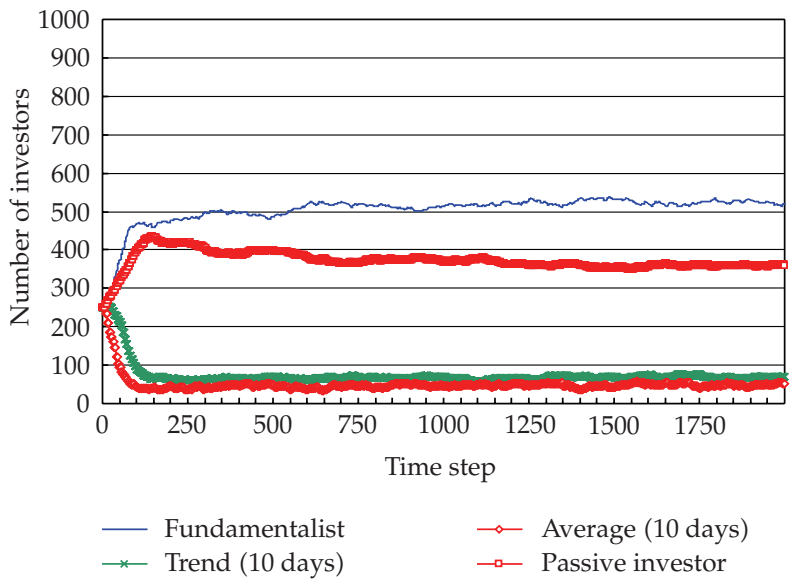

Figure 16: Transition of the number of investors (mutation: $3 \%, \sigma_{n}=1 \%$ ).

investors who randomly change investment strategy, there is a corresponding increase in the number of fundamentalists. ${ }^{19}$ Figure 16 shows the transitions of the number of investors where the rate of investors who randomly change investment strategy is $3 \%$. This shows that the number of fundamentalists increases even further, exceeding the number of investors who conduct passive investment strategy. ${ }^{20}$ In real markets, the effectiveness of passive investment strategy has widely been recognized from the viewpoint of practical business affairs as well as the academic standpoint. However, when the entire market is focused on, the rate of investors that adopt passive investment strategy is not always high. These results suggest that the existence of various sources of excess earnings should be included as one of the factors for the low ratio of passive investors. These are interesting results from both business and academic viewpoints. $^{21}$ 


\section{Summary}

Using analyses of agent-based model, this research looked at the influence of the difference in the forecast accuracy of fundamental values on financial markets. As a result of this computer-based market analysis, the following findings were made: (1) improvements in the forecast accuracy of fundamentalists can contribute to an increase in the number of fundamentalists; (2) certain situations might occur, according to the level of the forecast accuracy of fundamentalists, in which fundamentalists and passive management coexist, or in which fundamentalists die out of the market, and furthermore; (3) where a variety of investors exist in the market, improvements in forecast accuracy could increase the number of fundamentalists more than the number of investors that conduct passive investment strategy. These results contribute to clarifying the mechanism of price fluctuations in financial markets and also indicate one of the factors for the low ratio of passive investors in real financial markets. At the same time, they indicate that agent-based modeling is effective in conducting analyses in the field of financial studies. The results obtained in this analysis have significant meaning from both an academic and a practical business viewpoint. A more detailed analysis that considers the actual investment environment should be included in future research.

\section{List of Parameters}

This section lists the major parameters of the financial market designed for this paper. The explanation and value for each parameter is described.

\section{Parameters Abbreviations}

M: $\quad$ Number of investors (1000)

$N$ : Number of shares (1000)

$F_{t}^{i}$ : Total asset value of investor $i$ for term $t\left(F_{0}^{i}=2000\right.$ : common $)$

$W_{t}$ : Ratio of stock in benchmark for term $t\left(W_{0}=0.5\right)$

$w_{t}^{i}$ : Stock investment rate of investor $i$ for term $t\left(w_{0}^{i}=0.5\right.$ : common)

$y_{t}$ : $\quad$ Profits generated during term $t\left(y_{0}=0.5\right)$

$\sigma_{y}: \quad$ Standard deviation of profit fluctuation $(0.2 / \sqrt{200})$

$\delta: \quad$ Discount rate for stock $(0.1 / 200)$

$\lambda$ : $\quad$ Degree of investor risk aversion (1.25)

$\sigma_{n}:$ Standard deviation of dispersion from short-term expected rate of return on shares (0.01-0.03)

a: $\quad$ Degree of selection pressure (10)

c: Adjustment coefficient (0.01)

$r_{t}^{i m}:$ Expected rate of share return as estimated from risk etc.

$\sigma_{t}^{s}$ : Assessed value of standard deviation of share fluctuation

$\sigma_{t}^{h}: \quad$ Historical volatility of shares

$P_{t}$ : $\quad$ Transaction prices for term $t$

$P_{t}^{f(, i)}$ : Forecast value of transaction prices (of investor $i$ ) for term $t$

$y_{t}^{f(, i)}$ : Forecast value of profits (of investor $i$ ) for term $t$

$r^{f(i)}$ : Short-term expected rate of return on shares (of investor $i$ )

$a_{t}$ : $\quad$ Price trend on stock until term $t$

$r_{i}^{\text {cum: }}$ Cumulative excess return of investor $i$ for the most recent five terms

$p_{i}$ : Probability that investorsf who alter their strategy will adopt investor ifs strategy. 


\section{Endnotes}

1. CAPM is also applied frequently to evaluate the enterprise value in Mergers and Acquisitions (M\&A) [23].

2. Passive investment strategy has been well-known in the actual asset management businesses. On the other hand, active investment strategy that tries to obtain excess earnings using investments has been widely prevalent. There also exist investment trust funds that look for their basis of conducting active management in behavioral finance.

3. In the case of a financial market, investors represent agents and a stock market represents a multiagent system $[17,24]$.

4. Buy-and-hold method is an investment method to hold shares for medium to long term.

5. This analysis covered major types of investor behavior as the analysis object [9].

6. The value of objective function $f\left(w_{t}^{i}\right)$ depends on the investment ratio $\left(w_{t}^{i}\right)$. The investor decision-making model here is based on the Black/Litterman model that is used in the practice of securities investment $[19,25]$.

7. In the actual market, evaluation tends to be conducted according to baseline profit and loss.

8. Selection pressures on an investment strategy become higher as the coefficients' value increases.

9. This is one of the characteristics of agent-based modeling where such an analysis can be conducted.

10. Where the forecast accuracy $\left(\sigma_{n}\right)$ is $0 \%$, there are no forecast errors by fundamentalists.

11. In other words, these results show that the rate of increase in the number of fundamentalists is influenced by the forecast dispersion of other investors.

12. A detailed analysis of the forecast accuracy of fundamentalists and the forecast dispersion of other investors needs to be carried out in the future.

13. See Takahashi et al. [6] for a detailed analysis of the influence of passive investment strategy on stock markets.

14. Under the present conditions, where the estimation accuracy of fundamentalists $\left(\sigma_{n}\right)$ is $1 \%$ and $2 \%$, all the investors conduct passive investment strategy in either case. In this sense, under the present conditions, the estimation accuracy of fundamentalists $\left(\sigma_{n}\right)$ does not have any impact on whether or not fundamentalists can survive in the market.

15. Such a mechanism that works can make it possible for investors other than fundamentalists to always exist in the market.

16. In this case, transaction prices are consistent with fundamental values.

17. In the case under discussion here, market transactions consist of funds transferred between fundamentalists and other kinds of investors. The existence of various investors serves to provide the source of excess earnings for fundamentalists. These transactions serve to determine transaction prices and therefore conform to fundamental values.

18. The increase in the rate of investors who randomly change investment strategy means that there are more investors whose investments are based on trends and past averages in the market.

19. In this case, transaction prices are consistent with fundamental values. 
20. This paper analyzes the relationship between microbehavior and macrobehavior under conditions where market prices are consistent with fundamental values. Analyzing the market under other conditions, such as when fundamentalists are eliminated from the market, will form part of our future work [17].

21. These results provide a significant suggestion with regard to the meaning of conducting active investment strategy.

\section{References}

[1] H. Markowitz, "Portfolio Selection," Journal of Finance, vol. 7, pp. 77-91, 1952.

[2] W. F. Sharpe, "Capital asset prices: a theory of market equilibrium under condition of risk," The Journal of Finance, vol. 19, pp. 425-442, 1964.

[3] F. Black and M. Scholes, "Pricing of options and corporate liabilities," Bell Journal of Economics and Management Science, vol. 4, pp. 141-183, 1973.

[4] J. E. Ingersoll, Theory of Financial Decision Making, Rowman \& Littlefield, Lanham, Md, USA, 1987.

[5] E. Fama, "Efficient capital markets: a review of theory and empirical work," Journal of Finance, vol. 25, pp. 383-417, 1970.

[6] H. Takahashi, S. Takahashi, and T. Terano, "Agent-based modeling to investigate the effects of passive investment strategies in financial markets," in Social Simulation Technologies: Advances and New Discoveries, B. Edmonds, C. Hernandes, and K. Troitzsch, Eds., pp. 224-238, Idea Group, 2007, Representing the best of the European Social Simulation Association conferences.

[7] D. Kahneman and A. Tversky, "Prospect theory of decisions under risk," Econometrica, vol. 47, pp. 263-291, 1979.

[8] A. Tversky and D. Kahneman, "Advances in prospect theory: cumulative representation of uncertainty," Journal of Risk and Uncertainty, vol. 5, no. 4, pp. 297-323, 1992.

[9] A. Shleifer, Inefficient Markets, Oxford University Press, Oxford, UK, 2000.

[10] R. J. Shiller, Irrational Exuberance, Princeton University Press, Princeton, NJ, USA, 2000.

[11] R. Axtell, Why Agents? On the Varied Motivation for Agent Computing in the Social Sciences, Working Paper no.17, Brookings Institution Center on Social and Economic Dynamics, 2000.

[12] S. J. Russel and P. Norvig, Artificial Intelligence, Prentice-Hall, Upper Saddle River, NJ, USA, 1995.

[13] J. M. Epstein and R. Axtell, Growing Artificial Societies Social Science from the Bottom Up, MIT Press, Cambridge, Mass, USA, 1996.

[14] W. B. Arthur, J. H. Holland, B. LeBaron, R. G. Palmer, and P. Taylor, "Asset pricing under endogenous expectations in an artificial stock market," in The Economy as an Evolving Complex System II, pp. 15-44, Addison-Wesley, Reading, Mass, USA, 1997.

[15] R. Axelrod, The Complexity of Cooperation-Agent-Based Model of Competition and Collaboration, Princeton University Press, Upper Saddle River, NJ, USA, 1997.

[16] L. Tesfatsion, Agent-Based Computational Economics, Economics Working Paper, No.1, Iowa Sate University, Iowa, Miss, USA, 2002.

[17] H. Takahashi and T. Terano, "Agent-based approach to investors' behavior and asset price fluctuation in financial markets," Journal of Artificial Societies and Social Simulation, vol. 6, no. 3, 2003.

[18] P. O'Brien, "Analysts' forecasts as earnings expectations," Journal of Accounting and Economics, pp. 53-83, 1988.

[19] F. Black and R. Litterman, "Global portfolio optimization," Financial Analysts Journal, pp. 28-43, 1992.

[20] W. F. Sharpe, "Integrated asset allocation," Financial Analysts Journal, pp. 25-32, 1987.

[21] D. Goldberg, Genetic Algorithms in Search, Optimization, and Machine Learning, Addison-Wesley, Reading, Mass, USA, 1989.

[22] H. Takahashi and T. Terano, "Analysis of micro-macro structure of financial markets via agent-based model: risk management and dynamics of asset pricing," Electronics and Communications in Japan, Part II, vol. 87, no. 7, pp. 38-48, 2004.

[23] R. Brealey, S. Myers, and F. Allen, Principles of Corporate Finance, McGraw-Hill, New York, NY, USA, 8th edition, 2006.

[24] M. Levy, H. Levy, and S. Solomon, Microscopic Simulation of Financial Markets, Academic Press, Boston, Mass, USA, 2000.

[25] L. Martellini and V. Ziemann, "Extending black-litterman analysis beyond the mean-variance framework: an application to hedge fund style active allocation decisions," Journal of Portfolio Management, vol. 33, no. 4, pp. 33-45, 2007. 


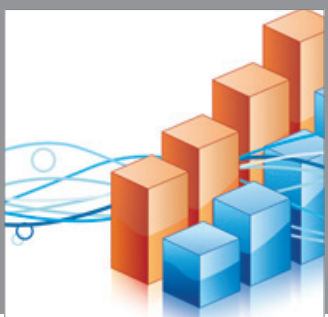

Advances in

Operations Research

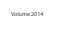

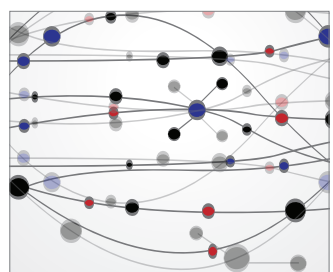

\section{The Scientific} World Journal
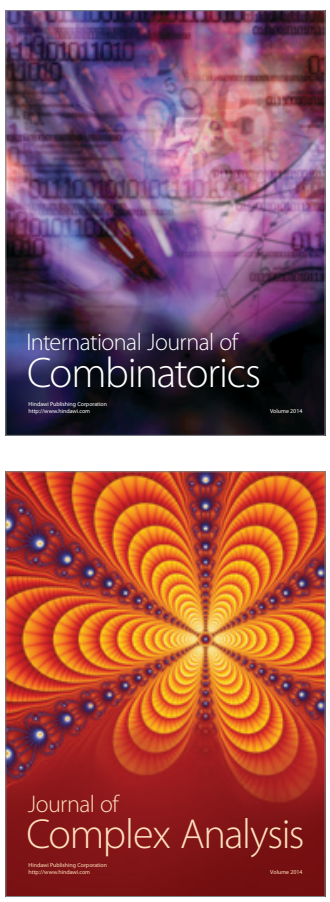

International Journal of

Mathematics and

Mathematical

Sciences
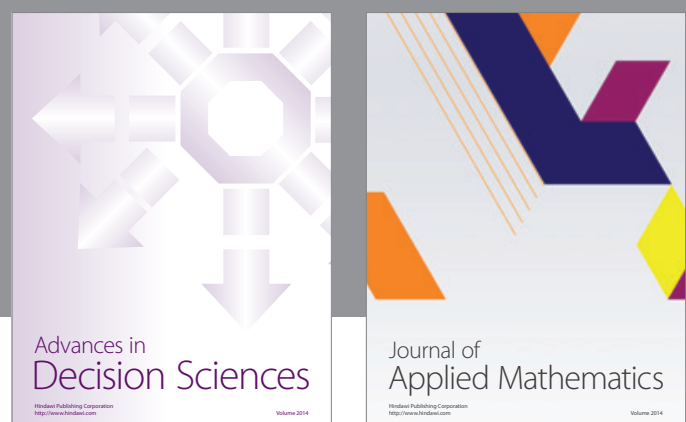

Journal of

Applied Mathematics
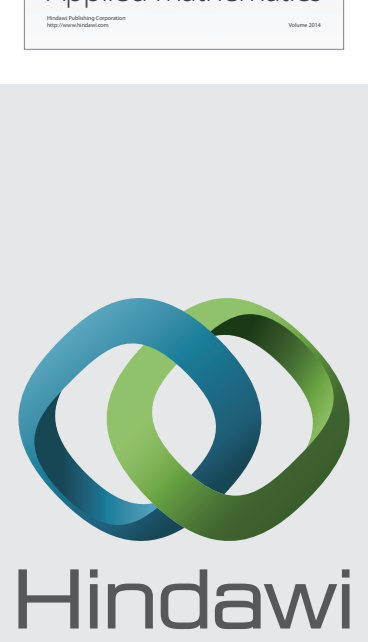

Submit your manuscripts at http://www.hindawi.com
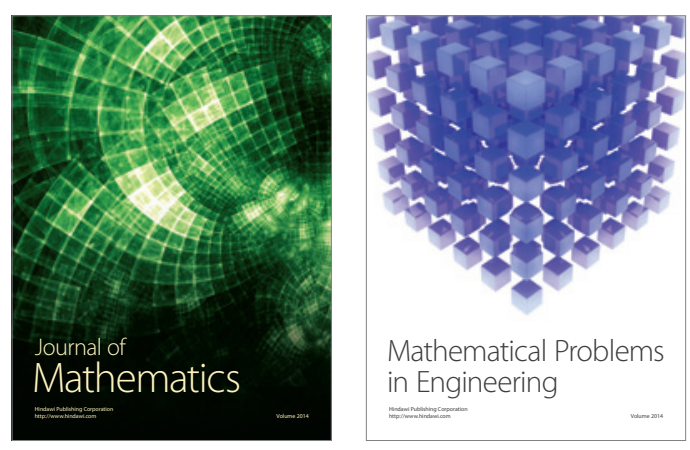

Mathematical Problems in Engineering
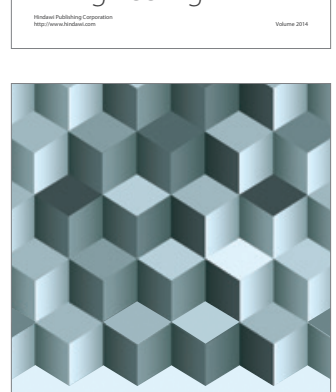

Journal of

Function Spaces
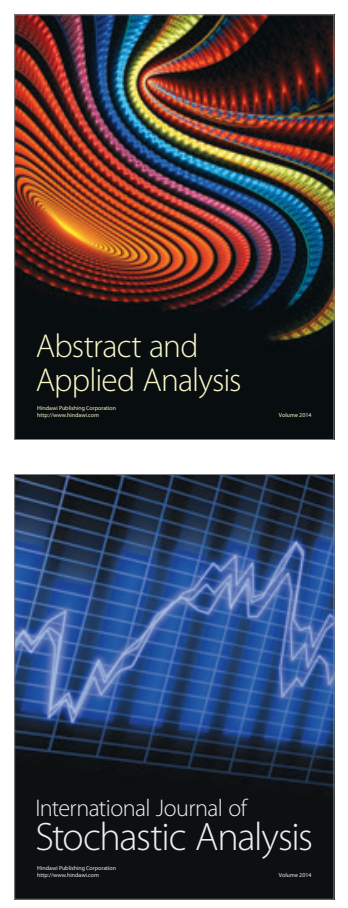

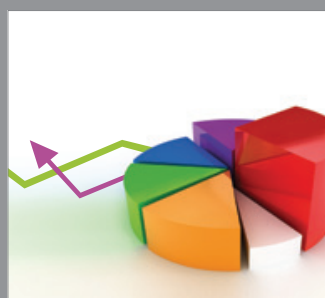

ournal of

Probability and Statistics

Promensencen
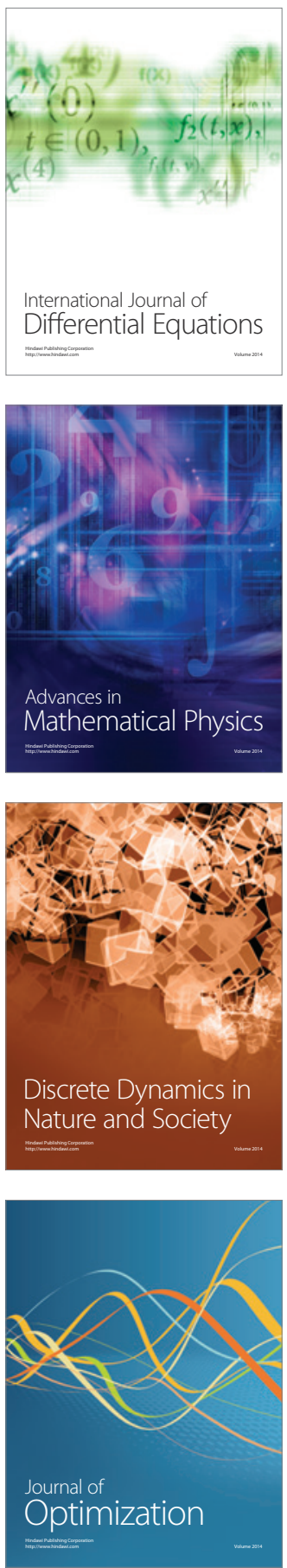